\title{
An Integrated Index Combined by Dynamic Hyperinflation and Exercise Capacity in the Prediction of Morbidity and Mortality in COPD
}

\author{
Eylem Sercan Özgür MD, Sibel Atış Naycı MD, \\ Cengiz Özge MD, and Bahar Taşdelen PhD
}

\begin{abstract}
BACKGROUND: Dynamic hyperinflation (DH) and exercise limitation develop in patients with COPD; however, there is lack of knowledge about their long-term clinical consequences. We aimed to assess the impact of DH and exercise capacity in predicting mortality and also morbidity, as evaluated by emergency visits and hospital admissions in COPD patients during a 4-year period. METHODS: We recruited 73 stable COPD patients. The relationships of different respiratory parameters $\left(\mathrm{FEV}_{1} \%\right.$, body mass index, 6 min walk test distance [6MWD], static hyperinflation as measured by the ratio of inspiratory capacity to total lung capacity (IC/TLC) at rest, DH as measured by the change between the post- and pre-exercise values of IC/TLC [ $\Delta \mathrm{IC} / \mathrm{TLC}], \mathrm{P}_{\mathrm{aO}}$, and $\mathbf{P}_{\mathrm{aCO}_{2}}$ ) with emergency visits and hospital admissions because of exacerbations and also with respiratory and all-cause mortality were assessed. RESULTS: The median follow-up period was 47 months (IQR 45-48 months, $n=73$ ). During the follow-up there were 8 (11\%) deaths. The $\Delta$ IC/TLC value was $3.9 \pm 4.6 \%$. The Kaplan-Meier survival curve showed that the cumulative survival rate was significantly lower in the patients with $\triangle \mathrm{IC} / \mathrm{TLC}>4$ and with $6 \mathrm{MWD} \leq 439.56 \mathrm{~m}$, using these values as thresholds. (The rates for sensitivity were $100 \%$ and $87.5 \%$, and for specificity were $56.92 \%$ and $\mathbf{8 7 . 6 9 \%}$, respectively). The Cox proportional hazards model showed that DH (hazard ratio $=1.4,95 \% \mathrm{CI}=1.09-1.84, P=.009)$ and $6 \mathrm{MWD}($ hazard ratio $=0.98,95 \% \mathrm{CI}=0.97$ $0.99, P=.006)$ were independent predictors of all-cause and respiratory mortality. $6 \mathrm{MWD}, \mathrm{FEV}_{1} \%$, IC/TLC, and $\triangle I C / T L C$ were found to be significantly related to emergency visits $(r=-0.28, r=$ $-0.41, r=-0.24$, and $r=0.38$, respectively) and hospital admissions $(r=-0.41, r=-0.45, r=$ -0.36 , and $r=0.28$, respectively). CONCLUSIONS: DH and exercise capacity are reliable and independent predictors for mortality and morbidity in COPD patients. We propose that DH and exercise capacity be considered in the assessment of long-term clinical consequences of COPD patients. Key words: COPD; dynamic hyperinflation; exercise capacity; emergency visit; hospital admission; morbidity; mortality. [Respir Care 2012;57(9):1452-1459. () 2012 Daedalus Enterprises]
\end{abstract}

\section{Introduction}

COPD is an important cause of chronic morbidity and mortality worldwide. Many people suffer from this disease for years and die prematurely from it or its complications.

\footnotetext{
The authors are affiliated with the Department of Chest Diseases, Mersin University School of Medicine, Mersin, Turkey; with the exception of Dr Taşdelen, who is affiliated with the Department of Biostatistics at that institution.
}

The authors have disclosed no conflicts of interest.
It is the fourth leading cause of death in the world, and further increases in mortality of COPD are expected in the coming decades..$^{1,2}$

Several studies have shown that the $\mathrm{FEV}_{1}$ and diminished $\mathrm{FEV}_{1}$, hypoxemia, exercise capacity, body mass in-

Correspondence: Eylem Sercan Ozgur MD, Mersin Universitesi Tip Fakültesi, Göğüs Hastalıkları AD, 33079, Mersin, Turkey. E-mail: eylemozgur@yahoo.com.

DOI: $10.4187 /$ respcare. 01440 


\section{An Integrated Index Combined by Dynamic Hyperinflation and EXercise Capacity}

dex (BMI), dyspnea index, and physical activity predict morbidity and mortality in COPD patients. ${ }^{3-7}$ Celli et al reported excellent predictive value of the multidimensional BODE (BMI, air-flow obstruction, dyspnea, exercise performance) index, which incorporates these variables into a single score. ${ }^{7}$ Identification and amelioration of predictors for COPD morbidity and mortality may improve longterm outcomes.

Pulmonary hyperinflation is usually defined as an abnormal increase of lung volume at the end of tidal expiration. The reduced elastic lung recoil, increased airways resistance, and development of expiratory flow limitation promote progressive air trapping, with an increase in the end-expiratory lung volume and a decrease in inspiratory capacity (IC). The resting IC is accepted as a reflection of end-expiratory lung volume. ${ }^{8}$ Static hyperinflation can be determined by measuring IC and/or the ratio of IC to total lung capacity (IC/TLC). ${ }^{8-10}$ Its increase during exercise is defined as dynamic hyperinflation (DH). During exercise, as ventilatory demand increases in flow-limited patients, progressive air trapping and further $\mathrm{DH}$ above the already increased resting value is inevitable. ${ }^{11}$ As the 6-min walk test (6MWT) is a reliable and more practical test to assess the fictional status of patients with COPD, it has become a popular alternative tool to the more formal cardiopulmonary exercise test. Some studies have demonstrated that DH can be assessed during a 6MWT.9,12,13

Static and dynamic lung hyperinflation have been associated with limitation in the functional capacity of COPD patients. ${ }^{4,8,9,11-13}$ It has been shown that dynamic lung hyperinflation has important clinical consequences in patients with COPD, such as dyspnea, pulmonary gas exchange impairment, increased ventilatory demand, expiratory muscle weakness, reduced exercise performance, daily physical activity, and impaired quality of life. ${ }^{11,14-16} \mathrm{~A}$ few longitudinal studies have assessed the impact of pulmonary hyperinflation on the prognosis of COPD. Recently, 2 studies assessed the impact of static hyperinflation on mortality in COPD patients and found that it was an independent predictor of mortality 8,10 ; however, the possible value of $\mathrm{DH}$ in predicting survival has not been adequately evaluated.

We aimed to assess the impact of $\mathrm{DH}$ and exercise capacity in predicting mortality and also morbidity, as evaluated by emergency visits and hospital admissions because of exacerbations in patients with COPD during a 4 year period.

\section{Methods}

A prospective cohort study of COPD patients was undertaken at the Chest Disease Department of Mersin University, Mersin, Turkey. The study protocol was approved by the ethical committee of the Mersin University School

\section{QUICK LOOK}

\section{Current knowledge}

Dynamic hyperinflation in patients with COPD leads to exercise limitation and exercise intolerance. The relationship of exercise limitation to outcome is not well described.

\section{What this paper contributes to our knowledge}

Dynamic hyperinflation, measured by the ratio of the change in inspiratory capacity to total lung capacity $(\triangle \mathrm{IC} / \mathrm{TLC})$, and exercise capacity, measured by the 6-min walk test, are reliable and independent predictors for mortality and morbidity in COPD patients.

of Medicine. Written informed consent was obtained from all subjects before enrollment into the study.

We recruited 73 stable COPD patients, diagnosed according to the Global Initiative for Chronic Obstructive Lung Disease (GOLD) 2003 criteria, ${ }^{17}$ from October 2004 to June 2005. Criteria for participation included a diagnosis of COPD, an age of 40 years or more, a smoking history of at least 10 pack-years, a post-bronchodilator $\mathrm{FEV}_{1} / \mathrm{FVC}$ of $<70 \%$, and reversibility of $<200 \mathrm{~mL}$ or $<12 \%$ in $\mathrm{FEV}_{1}$ after inhalation of $200 \mu \mathrm{g}$ salbutamol. Patients who were stable in the last 6 weeks before entering the study, with moderate to very severe disease (postbronchodilator $\mathrm{FEV}_{1}<80 \%$ ) and taking optimal medical therapy, were included in the study. All subjects were assessed clinically and with a chest radiograph to ensure the absence of other important respiratory disease. Patients with an exacerbation or a recent respiratory-tract infection within the last 6 weeks, clinical history of asthma, atopy, allergic disease, bronchiectasis or other pulmonary disease, uncontrolled comorbidities likely to affect mortality, (such as malignant disorders, cardiovascular disease, or history of systemic disease); patients requiring long-term oxygen therapy or mechanical ventilation for respiratory failure; and patients with pulmonary rehabilitation history were excluded.

Pulmonary function tests, including spirometry and lung volumes measurements, were performed using computerassisted spirometry (Vmax 22D, SensorMedics, Yorba Linda, California), in accordance with the European Respiratory Society's recommendations. ${ }^{18}$ Lung volumes were measured by multiple-breath nitrogen washout technique. ${ }^{19}$ The multiple-breath nitrogen washout technique was performed by a medical doctor after the procedure had been fully explained to each patient. A waiting period of 1 hour was recommended between lung volumes measured in patients with severe obstructive disease. ${ }^{19}$ Thus, we performed 6MWT after 1 hour of pre-exercise pulmo- 


\section{An Integrated Index Combined by Dynamic Hyperinflation and EXercise Capacity}

nary function tests. Then, lung volume measurements were repeated immediately after the 6MWT. Static hyperinflation was measured by the IC/TLC at rest, and DH was measured by the change between post- and pre-exercise value of IC/TLC $(\Delta \mathrm{IC} / \mathrm{TLC}){ }^{8}$

Exercise capacity was evaluated with 6-min walk test, according to American Thoracic Society criteria. ${ }^{20}$ Arterial blood gas $\left(\mathrm{P}_{\mathrm{aO}_{2}}\right.$ and $\left.\mathrm{P}_{\mathrm{aCO}}\right)$ samples were taken at rest while breathing room air, then measured immediately using a blood gas analyzer (AVL Omni, Roche Diagnostic, Basel, Switzerland). ${ }^{21}$ Dyspnea was evaluated by baseline dyspnea index. ${ }^{22}$ Combined Charlson comorbidity index was used to determine the degree of comorbidity. ${ }^{23}$

Subjects were seen every 3-6 months or until death. The follow-up ended in January 2009. Respiratory and all-cause mortality, emergency visits because of exacerbations, and the number of hospitalizations were recorded during the follow-up period. Information was obtained by reviewing medical records and from family members. An exacerbation was defined as sustained worsening of the subject's condition from the stable state and beyond normal day-to-day variation and necessitating any change in medication. ${ }^{24}$ The relationships of different respiratory parameters $\left(\mathrm{FEV}_{1} \%\right.$, BMI, 6-min walk distance [6MWD], static hyperinflation, $\mathrm{DH}, \mathrm{P}_{\mathrm{aO}}$, and $\mathrm{P}_{\mathrm{aCO}_{2}}$ ) with emergency visits and hospital admissions because of exacerbations, and also with respiratory and all-cause mortality, were assessed.

\section{Statistical Analysis}

Statistical analyses were performed using statistics software (SPSS 11.5, SPSS, Chicago, Illinois, and MedCalc 9.6.4, clinical calculators at http://www.medcalc.com). Data are presented as mean $\pm \mathrm{SD}$. The baseline characteristics of the study subjects who died and those who remained alive were compared by using the unpaired Student $t$ test for continuous variables. Emergency visits and exacerbation-related hospital admissions of the patients were compared with the Mann-Whitney U test.

A receiver operating characteristic type II analysis, with mortality as the gold standard reference, was used to determine the better cutoff point for $\Delta \mathrm{IC} / \mathrm{TLC} .{ }^{25}$ KaplanMeier analysis for survival due to all and respiratory causes was performed with a $\triangle \mathrm{IC} / \mathrm{TLC}$ and $6 \mathrm{MWD}$ cutoff value according to the model of comparison between 2 sample groups, and the differences between curves were evaluated by the log-rank tests. We performed Cox proportional hazard regression analyses under the proportional hazards assumption to evaluate the cutoff value for $\triangle \mathrm{IC} / \mathrm{TLC}, 6 \mathrm{MWD}$, and integrated index (combined $\triangle \mathrm{IC} / \mathrm{TLC}$ and $6 \mathrm{MWD}$ ) to predict the risk of death. Multivariable regression analysis (Cox regression proportional hazards model) was used to determine the independent predictors of all-cause and re-
Table 1. Characteristics of Subjects With COPD $(n=73)$

\begin{tabular}{|c|c|}
\hline Male/female, no. & $63 / 10$ \\
\hline Age, y & $58.8 \pm 8.9$ \\
\hline Smoking history, pack-years & $43.4 \pm 12.1$ \\
\hline Body mass index, $\mathrm{kg} / \mathrm{m}^{2}$ & $25.7 \pm 4.4$ \\
\hline \multicolumn{2}{|l|}{ GOLD Stage, no. (\%) } \\
\hline II & $53(72.6)$ \\
\hline III & $16(21.9)$ \\
\hline IV & $4(5.5)$ \\
\hline FVC, $\%$ predicted & $93 \pm 14.4$ \\
\hline $\mathrm{FEV}_{1}, \%$ predicted & $62.2 \pm 13.4$ \\
\hline FRC, $\%$ predicted & $140.6 \pm 42.8$ \\
\hline \multicolumn{2}{|l|}{ IC, L } \\
\hline Pre-exercise & $2.5 \pm 0.7$ \\
\hline Post-exercise & $2.3 \pm 0.6$ \\
\hline \multicolumn{2}{|l|}{ TLC, L } \\
\hline Pre-exercise & $7.2 \pm 1.3$ \\
\hline Post-exercise & $7.7 \pm 1.4$ \\
\hline \multicolumn{2}{|l|}{ IC/TLC, \% } \\
\hline Pre-exercise & $35.1 \pm 10.6$ \\
\hline Post-exercise & $31.2 \pm 10.3$ \\
\hline$\Delta \mathrm{IC} / \mathrm{TLC}, \%$ & $3.9 \pm 4.6$ \\
\hline $\mathrm{P}_{\mathrm{aO}_{2}}, \mathrm{~mm} \mathrm{Hg}$ & $80.6 \pm 11.6$ \\
\hline $\mathrm{P}_{\mathrm{aCO}_{2}}, \mathrm{~mm} \mathrm{Hg}$ & $38.5 \pm 3.7$ \\
\hline Baseline dyspnea index & $8.9 \pm 1.8$ \\
\hline $6 \mathrm{MWD}, \mathrm{m}$ & $527 \pm 94.9$ \\
\hline Charlson comorbidity index (range) & $0.8 \pm 0.8(0-3)$ \\
\hline \multicolumn{2}{|l|}{$\begin{array}{l} \pm \pm \text { Values are mean } \pm \text { SD. } \\
\text { FRC }=\text { functional residual capacity } \\
\text { IC }=\text { inspiratory capacity } \\
\text { TLC }=\text { total lung capacity } \\
6 \mathrm{MWD}=6 \text {-min walk distance }\end{array}$} \\
\hline
\end{tabular}

spiratory mortality. Additionally, we computed the C statistic by means of a Cox model, as either dying or surviving. The null value for the $\mathrm{C}$ statistic is 0.5 , with a maximum of 1.0 (with higher values being better). The association of emergency visits and hospital admissions with clinical and functional parameters was determined using Spearman rank correlation analysis. Statistical significance was considered at $P<.05$ level.

\section{Results}

Demographic, clinical and spirometric characteristics are presented in Table 1. The median follow-up period was 47 months (IQR 45-48, $n=73$ ). During the follow-up there were $8(11 \%)$ deaths (Fig. 1), due to respiratory illness in $6(75 \%)$ patients, non-respiratory illness in 1 $(12.5 \%)$, and not identified in $1(12.5 \%)$.

The mean emergency visit frequency of patients was $2.75 \pm 1.75$ visits during the follow-up period in the deceased COPD group versus $0.72 \pm 1.32$ during the follow-up period in the alive COPD group during the fol- 


\section{An Integrated Index Combined by Dynamic Hyperinflation and Exercise Capacity}

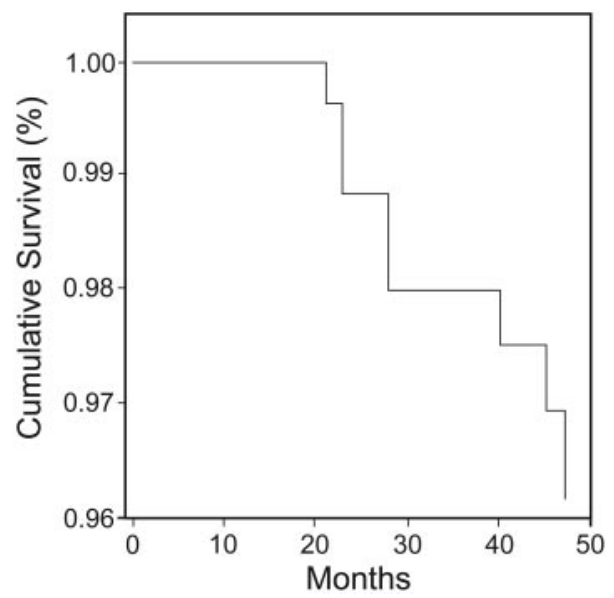

Fig. 1. Cumulative mortality. During the follow-up there were 8 (11\%) deaths.

Table 2. Clinical and Functional Characteristics of the Subjects With COPD According to Survival

\begin{tabular}{|c|c|c|c|}
\hline & $\begin{array}{c}\text { Alive } \\
(n=65)\end{array}$ & $\begin{array}{c}\text { Dead } \\
(n=8)\end{array}$ & $P$ \\
\hline Age, y & $58.4 \pm 9.1$ & $62.6 \pm 6.4$ & .21 \\
\hline Body mass index, $\mathrm{kg} / \mathrm{m}^{2}$ & $25.7 \pm 4.4$ & $26.2 \pm 5.4$ & .79 \\
\hline 6MWD, m & $533.2 \pm 95.9$ & $405.6 \pm 48$ & $<.001$ \\
\hline $\mathrm{FEV}_{1}, \%$ predicted & $62.2 \pm 13.6$ & $52.2 \pm 7.9$ & .02 \\
\hline IC/TLC, $\%$ & $35.2 \pm 9.8$ & $29.6 \pm 8.1$ & .13 \\
\hline$\Delta \mathrm{IC} / \mathrm{TLC}, \%$ & $3.9 \pm 2.8$ & $7.3 \pm 2.7$ & .002 \\
\hline Baseline dyspnea index & $9.4 \pm 1.9$ & $8.9 \pm 1.7$ & .44 \\
\hline $\mathrm{P}_{\mathrm{aO}_{2}}, \mathrm{~mm} \mathrm{Hg}$ & $85.4 \pm 7.7$ & $80 \pm 11.9$ & .07 \\
\hline $\mathrm{P}_{\mathrm{aCO}_{2}}, \mathrm{~mm} \mathrm{Hg}$ & $38.5 \pm 3.8$ & $38.6 \pm 3.3$ & .93 \\
\hline Comorbidity, Charlson index & $2(0-3)$ & $2(1-3)$ & .74 \\
\hline $\begin{array}{l} \pm \text { Values are mean } \pm \text { SD. } \\
6 \mathrm{MWD}=6 \text {-min walk distance } \\
\mathrm{IC}=\text { inspiratory capacity } \\
\mathrm{TLC}=\text { total lung capacity }\end{array}$ & & & \\
\hline
\end{tabular}

low-up period $(P<.001)$, and $17.8 \%$ of the patients had been hospitalized because of exacerbation. The frequency of hospitalization was $75 \%$ in the deceased COPD group, versus $11 \%$ in the alive COPD group. Median hospital stay was 13 days (IQR $10-16 \mathrm{~d}, n=10$ ) in the deceased COPD group, versus 7 days (IQR $5-8 \mathrm{~d}, n=11$ ) in the alive COPD group. Invasive mechanical ventilation was performed in 3 patients $(4.1 \%)$, who were in the deceased subjects group.

Clinical and functional characteristics of the subjects with COPD according to survival are shown in Table 2. Subjects who died had lower $\mathrm{FEV}_{1}$ levels, more $\mathrm{DH}$, and less 6MWD than those who survived.

According to the receiver operating characteristic curve analysis, cutoff points for $\triangle \mathrm{IC} / \mathrm{TLC}$ and $6 \mathrm{MWD}$ were obtained as $>4$ and $\leq 439.56$ m, respectively. The Kaplan-

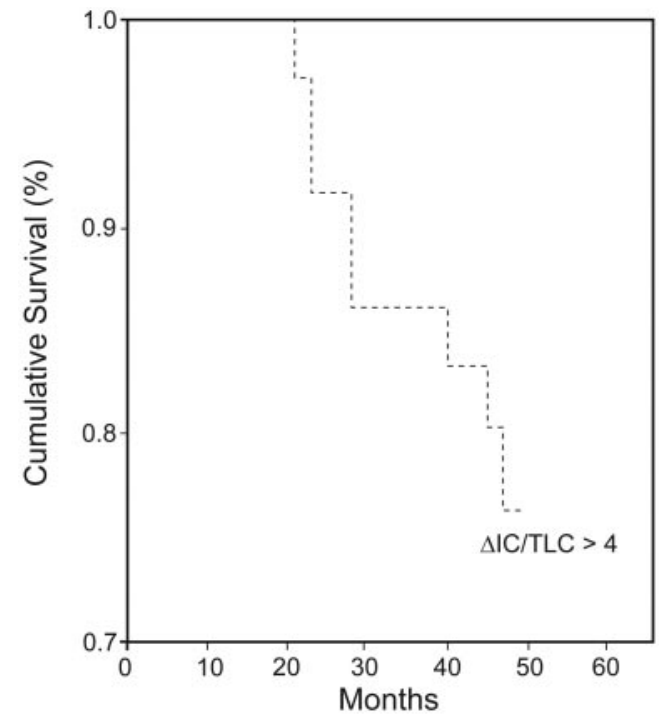

Fig. 2. Mortality rate according to dynamic hyperinflation. The Kaplan-Meier survival curve for all-cause mortality related to the change in the ratio of inspiratory capacity to total lung capacity $(\Delta \mathrm{IC} / \mathrm{TLC})$, using the 4 value as the threshold, is shown. A $P$ value for $\Delta \mathrm{IC} / \mathrm{TLC}$ could not be computed, since all the patients in the $\Delta \mathrm{IC} / \mathrm{TLC} \leq 4$ group survived.

Meier survival curve for all-cause mortality related to $\Delta \mathrm{IC} /$ TLC, using the 4 value as threshold, is shown in Figure 2. The cumulative survival rate was significantly lower in the COPD patients with $\triangle \mathrm{IC} / \mathrm{TLC}>4$. The sensitivity and specificity rates of $\Delta \mathrm{IC} / \mathrm{TLC}$ are $100 \%$ (95\% CI 62.9 $100.0 \%$ ) and $56.92 \%$ (95\% CI 44.0-69.1\%), respectively. The Kaplan-Meier survival curve for all-cause mortality shows that mortality rate was also related to $6 \mathrm{MWD}$, using the value of $439.56 \mathrm{~m}$ as the threshold (Fig. 3). The sensitivity and specificity rates of 6MWD were $87.5 \%(95 \% \mathrm{CI}$ 47.4-97.9\%) and $87.69 \%$ (95\% CI 77.2-94.5\%), respectively.

Additionally, we used an integrated index that combined DH and exercise capacity to predict exacerbations and survival. This integrated index was found to be more specific to predict for mortality, as compared to $\mathrm{DH}$ or exercise capacity alone (Fig. 4, Table 3 ). The sensitivity and specificity rates of this integrated index were $87.5 \%$ (95\% CI $47.38-97.93 \%$ ) and $96.9 \%$ (95\% CI 89.30 $99.54 \%$ ), respectively. The $\mathrm{C}$ statistic for the ability of the our integrated index to predict the risk of death was 0.92 as compared with a value of 0.79 with the use of DH alone, and with a value of 0.88 with the use of $6 \mathrm{MWD}$ alone.

On the basis of multivariable regression analysis (Cox regression proportional hazards model), DH (hazard ratio $=1.4,95 \% \mathrm{CI}=1.09-1.84, P=.009)$ and $6 \mathrm{MWD}$ (hazard ratio $=0.98,95 \% \mathrm{CI}=0.97-0.99, P=.006$ ) were found to be independent predictors of all-cause and respiratory mortality (Table 4). Compared to the patient 


\section{An Integrated Index Combined by Dynamic Hyperinflation and Exercise Capacity}

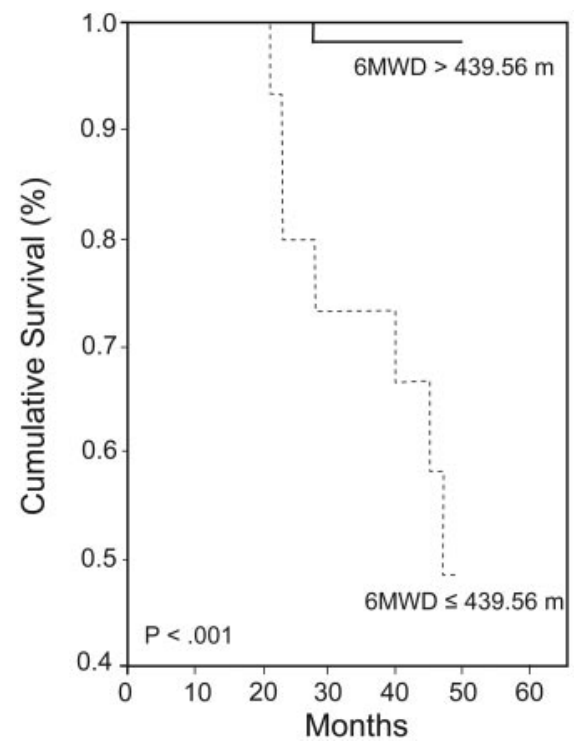

Fig. 3. Mortality rate according to 6-min walk distance (6MWD). The Kaplan-Meier survival curve for all-cause mortality related to $6 M W D$, using the $439.56 \mathrm{~m}$ value as the threshold, is shown. Using the log rank $P$ value to compare these curves, there was a significant difference between the 2 groups in terms of survival.

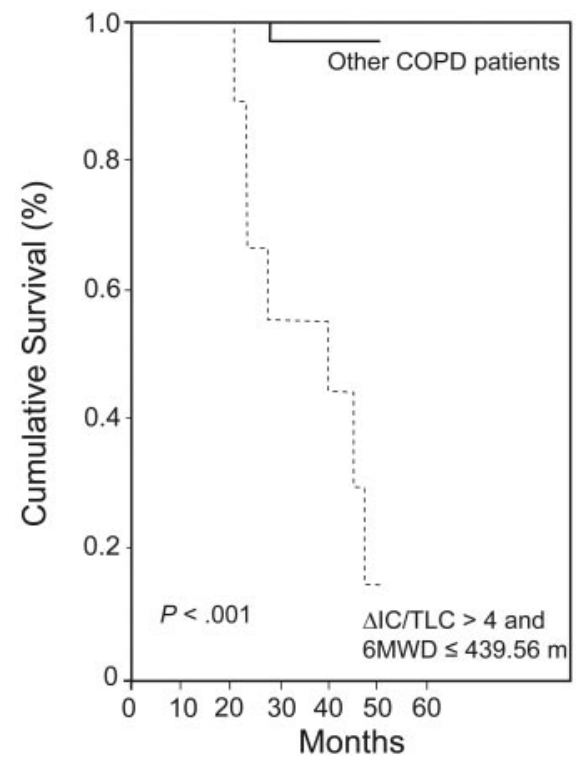

Fig. 4. Mortality rate according to our integrated index that combines DH and exercise capacity. The Kaplan-Meier survival curve for all-cause mortality related to our integrated index is shown. Using the log rank $P$ value to compare these curves, the cumulative survival rate was significantly lower in the COPD patients whose change in the ratio of inspiratory capacity to total lung capacity $(\Delta \mathrm{IC} / \mathrm{TLC})$ was $>4$ and whose 6 -min walk distance (6MWD) was $\leq 439.56 \mathrm{~m}$, compared to the other COPD patients.

group with $\Delta \mathrm{IC} / \mathrm{TLC} \leq 4$, the patients with $\Delta \mathrm{IC} / \mathrm{TLC}>4$ were more likely to have a shorter time to death (see Table 3).
6MWD, $\mathrm{FEV}_{1} \%, \mathrm{P}_{\mathrm{aCO}_{2}}, \mathrm{IC} / \mathrm{TLC}$, and $\triangle \mathrm{IC} / \mathrm{TLC}$ were found to be significantly related to morbidity and emergency visits. In addition, 6MWD, BMI, $\mathrm{FEV}_{1} \%$, IC/TLC, and $\triangle \mathrm{IC} / \mathrm{TLC}$ were found to be significantly associated with exacerbation-related hospital admissions (Table 5).

\section{Discussion}

In this study, different clinical and physiologic parameters $\left(\mathrm{FEV}_{1} \%\right.$, BMI, 6MWD, baseline dyspnea index, $\mathrm{P}_{\mathrm{aO}}$, $\mathrm{P}_{\mathrm{aCO}_{2}}$, static and DH) were assessed. $\mathrm{FEV}_{1}$, walk distance, and DH were found to be significant risk factors for mortality, emergency visits, and hospital admissions related to exacerbations. On the other hand, static hyperinflation was found to be correlated with emergency visits and hospital admissions because of exacerbations; however, this was not found to be a statistically significant risk factor for mortality.

It was assumed that DH was related to poor dyspnea, exercise capacity, daily physical activity, and quality of life ${ }^{11,14-16}$; however, no study has evaluated the effects of DH on COPD prognosis. Garcia-Rio et al identified DH and distance walked during $6 \mathrm{~min}$ as significant predictors of physical activity in moderate to very severe patients. The development of DH makes patients breathe at larger operational volumes, which results in an increase in respiratory effort, greater neuromechanical dissociation, and a greater perception of dyspnea. ${ }^{13,26}$ At the same time, DH contributes to the weakness and fatigue of the respiratory muscles ${ }^{26}$ and promotes deconditioning. Additionally, much pulmonary pathophysiological impairment occurs due to the inactivity, and patients therefore enter into a vicious circle. This configures a cycle of inactivity, deconditioning, and dyspnea that can cause the disease to worsen and progress. ${ }^{13}$

To best of our knowledge, this is the first study reporting that $\mathrm{DH}$ is an independent predictor of all-cause and respiratory mortality in patients with COPD. This study also shows that $\mathrm{DH}$ is related to emergency visits and hospital admissions because of COPD exacerbations. Indeed, these findings are not surprising. Static hyperinflation has been recently shown as an important mortality and morbidity predictor in the 2 large cohorts of COPD patients. ${ }^{8} 10$ Tantucci et al found that IC (percent of predicted) was a powerful functional predictor of all-cause and respiratory mortality, and of exacerbation-related hospital admissions in COPD patients. They concluded that parameters reflecting changes in lung volume (IC and IC/ TLC) were more sensitive and specific in predicting mortality in COPD patients than those reflecting air-flow obstruction $\left(\mathrm{FEV}_{1}\right.$ and $\left.\mathrm{FEV}_{1} / \mathrm{FVC}\right) .{ }^{10}$ Casanova et al also showed that static hyperinflation measured as IC/TLC was an independent predictor of mortality in COPD. ${ }^{8}$ 


\section{An Integrated Index Combined by Dynamic Hyperinflation and EXercise Capacity}

Table 3. Mean Survival Time and 95\% Confidence Interval Estimations for Dynamic Hyperinflation, 6MWT, and Integrated Index

\begin{tabular}{|c|c|c|c|c|c|c|c|c|c|}
\hline & Dead & Alive & $\begin{array}{c}\text { Mean } \\
\text { Survival }\end{array}$ & $95 \% \mathrm{CI}$ & $P$ & $\begin{array}{l}\text { Sensitivity } \\
\%(95 \% \text { CI) }\end{array}$ & $\begin{array}{l}\text { Specificity } \\
\%(95 \% \text { CI) }\end{array}$ & $\begin{array}{c}\text { Positive } \\
\text { Predictive Value } \\
\%(95 \% \text { CI })\end{array}$ & $\begin{array}{c}\text { Negative } \\
\text { Predictive Value } \\
\%(95 \% \mathrm{CI})\end{array}$ \\
\hline \multicolumn{10}{|l|}{$\Delta \mathrm{IC} / \mathrm{TLC}, \%$} \\
\hline$\leq 4$ & 0 & 37 & NA & NA & \multirow[t]{2}{*}{ NA } & 100 & 56.92 & 22.22 & 100 \\
\hline$>4$ & 8 & 28 & 45.16 & $42.39-47.94$ & & $(62.9-100)$ & $(44-69.1)$ & (10.14-39.16) & $(9042-100.00)$ \\
\hline \multicolumn{10}{|l|}{ 6MWD, m } \\
\hline$>439.56$ & 1 & 57 & 49.62 & $48.88-50.36$ & \multirow[t]{2}{*}{$<.001$} & 87.5 & 87.69 & 46.67 & 98.28 \\
\hline$\leq 439.56$ & 7 & 8 & 41.14 & $35.65-46.62$ & & $(47.4-97.9)$ & $(77.2-94.5)$ & $(21.34-73.35)$ & $(90.73-99.71)$ \\
\hline \multicolumn{10}{|l|}{ Integrated Index } \\
\hline Other COPD patients & 1 & 63 & 49.66 & $48.99-50.32$ & \multirow[t]{2}{*}{$<.001$} & 87.5 & 96.9 & \multirow{2}{*}{$\begin{array}{c}77.78 \\
(40.06-96.53)\end{array}$} & \multirow{2}{*}{$\begin{array}{c}98.44 \\
(91.57-99.74)\end{array}$} \\
\hline $\begin{array}{r}\Delta \mathrm{IC} / \mathrm{TLC}>4 \text { and } \\
6 \mathrm{MWT} \leq 439.56\end{array}$ & 7 & 2 & 35.74 & $28.5-42.98$ & & (47.38-97.93) & (89.3-99.54) & & \\
\hline $\begin{array}{l}\mathrm{IC}=\text { inspiratory capacity } \\
\mathrm{TLC}=\text { total lung capacity } \\
6 \mathrm{MWD}=6 \text {-min walk distance } \\
\mathrm{NA}=\text { not applicable. Mean surv }\end{array}$ & . & 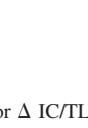 & 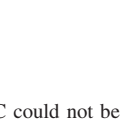 & & & group survived. & & & \\
\hline
\end{tabular}

Table 4. Independent Predictors of All-Cause (and Respiratory) Mortality*

\begin{tabular}{|c|c|c|c|}
\hline Variable & $\begin{array}{c}\text { Hazard } \\
\text { Ratio }\end{array}$ & $95 \% \mathrm{CI}$ & $P$ \\
\hline 6MWD & 0.98 & $0.97-0.99$ & .006 \\
\hline$\Delta \mathrm{IC} / \mathrm{TLC}$ & 1.4 & $1.09-1.84$ & .009 \\
\hline IC/TLC & 0.91 & $0.75-1.1$ & .39 \\
\hline $\mathrm{FEV}_{1}$ & 0.92 & $0.84-1.01$ & .08 \\
\hline Baseline dyspnea index & 1.05 & $0.58-1.91$ & .85 \\
\hline Body mass index & 1.25 & $0.93-1.68$ & .13 \\
\hline $\mathrm{P}_{\mathrm{aO}_{2}}$ & 0.9 & $0.66-1.22$ & .51 \\
\hline $\mathrm{P}_{\mathrm{aCO}_{2}}$ & 1.14 & $1.0-1.31$ & .053 \\
\hline \multicolumn{4}{|c|}{$\begin{array}{l}\text { * Multivariable Cox regression analyses. } \\
6 \mathrm{MWD}=6 \text {-min walk distance } \\
\text { IC }=\text { inspiratory capacity } \\
\text { TLC = total lung capacity }\end{array}$} \\
\hline
\end{tabular}

Our results also show that $\mathrm{FEV}_{1}$, when assessed alone, is a significant risk factor for mortality in COPD. However, $\mathrm{FEV}_{1}$ was not a significant risk factor for mortality when assessed with other clinical and functional parameters (BMI, 6MWD, baseline dyspnea index, $\mathrm{P}_{\mathrm{aO}}, \mathrm{P}_{\mathrm{aCO}_{2}}$, or static or dynamic hyperinflation). These findings support the reports of recent studies on this issue. In classical studies, $\mathrm{FEV}_{1}$ was the strongest factor in predicting mortality, compared with other variables (such as blood gases, pulmonary artery pressure). ${ }^{27,28}$ However, recent studies suggest that other parameters not explored previously (BMI, dyspnea, walk distance, health-related quality of life) independently predict outcome in COPD, and some are better predictors of this outcome than $\mathrm{FEV}_{1} \cdot{ }^{5,7,29-32}$

This study also shows that 6MWD is an independent predictor for mortality in COPD patients when assessed alone in the univariate analysis, and with other clinical and
Table 5. Predictors of Morbidity

\begin{tabular}{|c|c|c|c|c|}
\hline & \multicolumn{2}{|c|}{$\begin{array}{c}\text { Emergency Visits } \\
\text { Because of Exacerbations }\end{array}$} & \multicolumn{2}{|c|}{$\begin{array}{c}\text { Exacerbation-Related } \\
\text { Hospitalizations }\end{array}$} \\
\hline & $\mathrm{r}$ & $P^{*}$ & $\mathrm{r}$ & $P^{*}$ \\
\hline 6MWD & -0.28 & .02 & -0.41 & $<.001$ \\
\hline Body mass index & -0.06 & .63 & -0.24 & .03 \\
\hline IC/TLC & -0.24 & .04 & -0.36 & .002 \\
\hline$\Delta \mathrm{IC} / \mathrm{TLC}$ & 0.38 & .001 & 0.28 & .02 \\
\hline $\mathrm{FEV}_{1}$ & -0.41 & $<.001$ & -0.45 & $<.001$ \\
\hline $\mathrm{P}_{\mathrm{aCO}_{2}}, \mathrm{~mm} \mathrm{Hg}$ & 0.29 & .02 & 0.21 & .08 \\
\hline \multicolumn{5}{|c|}{$\begin{array}{l}\text { * Spearman's rank correlation test. } \\
6 \mathrm{MWD}=6 \text {-min walk distance } \\
\text { IC }=\text { inspiratory capacity } \\
\mathrm{TLC}=\text { total lung capacity }\end{array}$} \\
\hline
\end{tabular}

functional parameters in the multivariable regression analysis. Recent studies reported that 6MWD could be used to predict outcome in COPD, $, 29,30$ and that it was a better predictor of mortality than $\mathrm{FEV}_{1} \cdot{ }^{30}$ The present results are in agreement with the findings of Pinto et al. ${ }^{30}$

Combining other health measures with $\mathrm{FEV}_{1}$ provides a more complete view of COPD patients' clinical situation and prognosis. This was the rationale for the development of the BODE index, ${ }^{7}$ which has gained widespread acceptance in the medical community. Since then, several research groups have attempted to improve upon the BODE index with multidimensional instruments with greater predictive capacities. These include the Health, Activity, Dyspnea, Obstruction (HADO) score ${ }^{33}$ and the Age, Dyspnea, Obstruction (ADO) index. ${ }^{34}$ In this study we also evaluated an integrated index that combined $\mathrm{DH}$ and exercise capacity to predict morbidity and mortality, and we found that this integrated index was more specific to predict 


\section{An Integrated Index Combined by Dynamic Hyperinflation and EXercise Capacity}

mortality, as compared to DH or exercise capacity alone. Accordingly, we thought that the assessment of this integrated index may be more useful than a single parameter to predict the outcome of COPD patients. Compared to other multidimensional COPD prognostic indexes, our integrated index predicts mortality better than the BODE index (C statistic 0.92 vs 0.74$)^{7}$ and HADO index (C statistic 0.92 vs 0.68$).{ }^{33}$ However, the predictive capacity of this integrated index for mortality is not directly comparable with other multidimensional prognostic indexes in the literature, because the integrated index defined in this study includes different variables, such as DH and exercise capacity, and we had a limited sample.

The relationship between pulmonary DH and a higher risk of mortality in COPD patients is yet unknown, and further investigations are needed. Some hypothetic mechanisms, such as more frequent exacerbations and systemic involvement, are suggested in exploring the link between static hyperinflation and mortality. ${ }^{10}$ We believe that the same mechanisms could be related for DH and mortality, because COPD treatments that have been shown to reduce $\mathrm{DH}$ are also effective in decreasing exacerbations. ${ }^{35,36}$ There is also a decrease in morbidity and mortality with COPD treatments that reduce $\mathrm{DH}$, such as lung-volumereduction surgery and long-acting anticholinergics. ${ }^{35,37}$ The critical expiratory air-flow limitation with consequent DH seems to be the basic pathophysiology in COPD exacerbation. These changes lead to further derangement in ventilatory reserve, including mechanics, muscle function, and gas exchange. Increased DH is associated with lower ventilatory tolerance, and these patients cannot tolerate the ventilatory overload during exacerbations. Thus, COPD patients develop respiratory failure that is highly associated with the need for mechanical ventilation and with mortality. ${ }^{38}$

Our study had some advantages, as compared with similar studies, including long-term (mean 4 years) and close follow-up of the patients and, therefore, fuller knowledge of the causes of mortality. On the other hand, our study had some limitations. First, the total number of patients with at least stage III COPD was relatively low. Because of the relatively small sample in this study, we used select optimal cut points on a receiver operating characteristic curve for exercise capacity and DH data in the methodology, and these are subject to poor generalizability. Therefore, we propose that further validation of these cut points should be performed prior to clinical use. The second limitation was the use of multiple-breath nitrogen washout technique in the measurement of lung volumes. It was shown that plethysmographic lung volume measurement includes non-ventilated, as well as ventilated, lung compartments, and, thus, yields higher results than the gasdilution or washout methods. In patients with severe air- flow obstruction the true value of lung volumes is underestimated by the gas-dilution or washout methods. ${ }^{19}$ DH was measured in this study by means of consecutive IC recordings at the end of the exercise. Moreover, since DH decrease rapidly after the end of exercise ${ }^{9}$ and the multiple-breath nitrogen technique takes about $7 \mathrm{~min}$, our measurements probably underestimated the end-expiratory lung volumes. Maybe not only the magnitude of the augmentation in end-expiratory lung volume during the exercise, but also the normalization rate post-exercise contributed to the IC/TLC values observed.

\section{Conclusions}

In conclusion, DH and exercise capacity are reliable and independent predictors for mortality and are also related to morbidity in COPD patients. We propose that our integrated index that combines DH and exercise capacity should be considered in addition to other clinical and physiologic parameters in the assessment of long-term clinical course of patients with COPD.

\section{REFERENCES}

1. Rabe KF, Hurd S, Anzueto A, Barnes PJ, Buist SA, Calverley P, et al. Global strategy for the diagnosis, management, and prevention of chronic obstructive pulmonary disease: GOLD Executive Summary. Am J Respir Crit Care Med 2007;176(6):532-555.

2. European Respiratory Society. European lung white book. Lausanne, Switzerland: ERS; 2003.

3. Cote CG. Surrogates of mortality in chronic obstructive pulmonary disease. Am J Med 2006;119(10 Suppl 1):54-62.

4. Waschki B, Kirsten A, Holz O, Müller KC, Meyer T, Watz H, Magnussen $\mathrm{H}$. Physical activity is the strongest predictor of all-cause mortality in patients with chronic obstructive pulmonary disease: a prospective cohort study. Chest 2011;140(2):331-342.

5. Nishimura K, Izumi T, Tsukino M, Oga T. Dyspnea is a better predictor of 5-year survival than airway obstruction in patients with COPD. Chest 2002;121(5):1434-1440.

6. Celli BR. Predictors of mortality in COPD. Respir Med 2010;104(6): 773-779.

7. Celli BR, Cote C, Marin JM, Casanova C, Montes de Oca M, Mendez R, et al. The body mass index, airflow obstruction, dyspnea, and exercise capacity index in chronic obstructive pulmonary disease. N Engl J Med 2004;350(10):1005-1012.

8. Casanova C, Cote C, de Torres JP, Aguirre-Jaime A, Marin JM, Pinto-Plata V, et al. Inspiratory-to-total lung capacity ratio predicts mortality in patients whit chronic obstructive pulmonary disease. Am J Respir Crit Care Med 2005;171(6):591-597.

9. Callens E, Graba S, Gillet-Juvin K, Essalhi M, Bidaud-Chevalier B, Peiffer C, et al. Measurement of dynamic hyperinflation after a 6-minute walk test in patients with COPD. Chest 2009;136(6):1466-1472.

10. Tantucci C, Donati P, Nicosia F, Bertella E, Redolfi S, Vecchi M, et al. Inspiratory capacity predicts mortality in patients with chronic obstructive pulmonary disease. Respir Med 2008;102(4):613-619.

11. O'Donnell DE, Revill SM, Webb KA. Dynamic hyperinflation and exercise intolerance in chronic obstructive pulmonary disease. Am J Respir Crit Care Med 2001;164(5):770-777.

12. Marin JM, Carrizo SJ, Gascon M, Sanchez A, Gallego B. Inspiratory capacity, dynamic hyperinflation, breathlessness, and exercise per- 


\section{An Integrated Index Combined by Dynamic Hyperinflation and EXercise Capacity}

formance during the 6-minute-walk test in chronic obstructive pulmonary disease. Am J Respir Crit Care Med 2001;163(6):13951399.

13. Garcia-Rio F, Lores V, Mediano O, Rojo B, Hernanz A, LópezCollazo E et al. Daily physical activity in patients with chronic obstructive pulmonary disease is mainly associated with dynamic hyperinflation. Am J Respir Crit Care Med 2009;180(6):506-512.

14. O'Donnell DE, Laveneziana P. The clinical importance of dynamic lung hyperinflation in COPD. COPD 2006;3(4):219-232.

15. Calverley PM, Koulouris NG. Flow limitation and dynamic hyperinflation: key concepts in modern respiratory physiology. Eur Respir J 2005;25(1):186-199.

16. Calverley PM. Dynamic hyperinflation: is it worth measuring? Proc Am Thorac Soc 2006;3(3):239-244.

17. Global Initiative for Chronic Obstructive Lung Disease. Global strategy for the diagnosis, management, and prevention of chronic obstructive pulmonary disease: NHLBI/WHO (GOLD) Workshop report, NIH publication. US Department of Health and Human Service; 2003.

18. Quanjer PH, Tammeling GJ, Cotes JE, Pedersen OF, Peslin R, Yernault JC. Lung volumes and forced ventilatory flows. Report of the Working Party on Standardisation of Lung Function Tests, European Community for Steel and Coal. Official Statement of the European Respiratory Society Eur Respir J 1993;6(Suppl 16):5-40.

19. Wagner J, Clausen JL, Coates A, Pedersen OF, Brusasco V, Burgos F, et al; ATS/ERS Task Force. Standardization of the measurement of lung volumes. Eur Respir J 2005;26(3):511-522.

20. ATS Statement. Guidelines for the six-minute walking test. Am J Respir Crit Care Med 2002;166(1):111-117.

21. AARC Clinical Practice Guideline. Blood gas analysis and hemoximetry: 2001 revision and update. Respir Care 2001;46(5):498-505.

22. American Thoracic Society. Dyspnea, mechanisms, assessment, and management: a consensus statement. Am J Respir Crit Care Med 1999;159(1):321-340

23. Charlson M, Szatrowsky T, Peterson J, Gold J. Validation of a combined comorbidity index. J. Clin Epidemiol 1994;47(11):1245-1251.

24. Rodriguez-Roisin R. Toward a consensus definition for COPD exacerbations. Chest 2000;117(5 Suppl 2):398-401.

25. Hilgers RA. Distribution-free confidence bounds of ROC curves. Methods Inf Med 1991;30(2):96-101.
26. O'Donnell DE. Hyperinflation, dyspnea, and exercise intolerance in chronic obstructive pulmonary disease. Proc Am Thorac Soc 2006; 3(2):180-184.

27. Anthonisen NR, Wright EC, Hodgkin JE. Prognosis in chronic obstructive pulmonary disease. Am Rev Respir Dis 1986;133(1):14-20.

28. Traver GA, Cline MG, Burrows B. Predictors of mortality in chronic obstructive pulmonary disease. A 15-year follow-up study. Am Rev Respir Dis 1979;119(6):895-902.

29. Berry CE, Wise RA. Mortality in COPD: causes, risk factors, and prevention. COPD 2010;7(5):375-382.

30. Pinto-Plata VM, Cote C, Cabral H, Taylor J, Celli BR. The 6-min walk distance: change over time and value as a predictor of survival in severe COPD. Eur Respir J 2004;23(1):28-33.

31. Gerardi DA, Lovett L, Bennoti-Connors ML, Reardon JZ, Zu Wallack R. Variables related to increased mortality following out-patient pulmonary rehabilitation. Eur Respir J 1996;9(3):431-435.

32. Domingo- Salvany A, Lamarca R, Ferrer M, Garcia- Aymerich J, Alonso J, Felez M, et al. Health-related quality of life and mortality in male patients with chronic obstructive pulmonary disease. Am J Respir Crit Care Med 2002;166(5):680-685.

33. Esteban C, Quintana JM, Aburto M, Moraza J, Capelastegui A. A simple score for assessing stable chronic obstructive pulmonary disease. QJM 2006;99(11):751-759.

34. Puhan MA, Garcia-Aymerich J, Frey M, ter Riet G, Antó JM, Agustí AG, et al. Expansion of the prognostic assessment of patients with chronic obstructive pulmonary disease: the updated BODE index and the ADO index. Lancet 2009;374(9691):704-711.

35. Tashkin DP, Celli B, Senn S, Burkhart D, Kesten S, Menjoge S, et al. A four year trial of tiotropium in chronic obstructive pulmonary disease. N Engl J Med 2008;359(15):1543-1554.

36. Troosters T, Celli B, Lystig T, Kesten S, Mehra S, Tashkin DP, et al. Tiotropium as a first maintenance drug in COPD: secondary analysis of the UPLIFT trial. Eur Respir J 2010;36(1):65-73.

37. Fishman A, Martinez F, Naunheim K, Piantadosi S, Wisw R, Rise A, et al; National Emphysema Treatment Trial (NETT) Research Group. A randomised trial comparing lung-volume-reduction surgery with medical therapy for severe emphysema. N Engl J Med 2003;348(21): 2059-2073.

38. Reddy RM, Guntupalli KK. Review of ventilatory techniques to optimize mechanical ventilation in acute exacerbation of chronic obstructive pulmonary disease. Int J COPD 2007;2(4):441-452. 